\title{
Randomized controlled clinical trial of digital and conventional workflows for the fabrication of zirconia-ceramic posterior fixed partial dentures. Part II: Time efficiency of CAD-CAM versus conventional laboratory procedures
}

\author{
Mühlemann, Sven ; Benic, Goran I ; Fehmer, Vincent ; Hämmerle, Christoph H F ; Sailer, Irena
}

\begin{abstract}
STATEMENT OF PROBLEM Clinical trials are needed to evaluate the digital and conventional fabrication technology for providing fixed partial dentures (FPDs). PURPOSE The purpose of the second part of this clinical study was to compare the laboratory production time for tooth-supported, 3-unit FPDs by means of computer-aided design and computer-aided manufacturing (CAD-CAM) systems and a conventional workflow. In addition, the quality of the 3-unit framework of each treatment group was evaluated clinically. MATERIAL AND METHODS For each of 10 participants, a 3-unit FPD was fabricated. Zirconia was used as the framework material in the CAD-CAM systems and included Lava C.O.S. CAD software (3M) and centralized CAM (group L); CARES CAD software (Institut Straumann AG) and centralized CAM (group iT); and CEREC Connect CAD software (Dentsply Sirona) and centralized CAM (group C). The noble metal framework in the conventional workflow (group K) was fabricated by means of the traditional lost-wax technique. All frameworks were evaluated clinically before veneering. The time for the fabrication of the cast, the 3-unit framework, and the veneering process was recorded. In addition, chairside time during the clinical appointment for the evaluation of the framework was recorded. The paired Wilcoxon test together with appropriate Bonferroni correction was applied to detect differences among treatment groups $(\alpha=.05)$. RESULTS The total effective working time (mean \pm standard deviation) for the dental technician was $220 \pm 29$ minutes in group L, $217 \pm 23$ minutes in group iT, $262 \pm 22$ minutes in group $\mathrm{C}$, and $370 \pm 34$ minutes in group $\mathrm{K}$. The dental technician spent significantly more time in the conventional workflow than in the digital workflow, independent of the CAD-CAM systems used $(\mathrm{P}<.001)$. CONCLUSIONS Irrespective of the CAD-CAM system, the overall laboratory time for the dental technician was significantly less for a digital workflow than for the conventional workflow.
\end{abstract}

DOI: https://doi.org/10.1016/j.prosdent.2018.04.020

Posted at the Zurich Open Repository and Archive, University of Zurich ZORA URL: https://doi.org/10.5167/uzh-153079

Journal Article

Accepted Version

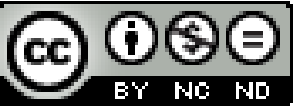

The following work is licensed under a Creative Commons: Attribution-NonCommercial-NoDerivatives 4.0 International (CC BY-NC-ND 4.0) License.

Originally published at:

Mühlemann, Sven; Benic, Goran I; Fehmer, Vincent; Hämmerle, Christoph H F; Sailer, Irena (2019). Randomized controlled clinical trial of digital and conventional workflows for the fabrication of zirconia-ceramic posterior 
fixed partial dentures. Part II: Time efficiency of CAD-CAM versus conventional laboratory procedures. Journal of Prosthetic Dentistry, 121(2):252-257.

DOI: https://doi.org/10.1016/j.prosdent.2018.04.020 
Randomized controlled clinical trial of digital and conventional workflows for the fabrication of zirconia-ceramic posterior fixed partial dentures. Part II: Time efficiency of CAD-CAM versus conventional laboratory procedures

Sven Mühlemann, Dr med dent, ${ }^{a}$ Goran I. Benic, PD Dr med dent, ${ }^{,}$Vincent Fehmer, MDT, Christoph H.F. Hämmerle, Prof Dr med dent, and Irena Sailer, Prof Dr med dent

Supported by the Clinic of Fixed and Removable Prosthodontics and Dental Material Science, Center of Dental Medicine, University of Zurich, Switzerland and by a research grant from Institut Straumann AG, Basel, Switzerland.

a Senior Teaching and Research Assistant, Clinic of Fixed and Removable Prosthodontics and Dental Material Science, Center of Dental Medicine, University of Zurich, Zurich, Switzerland ${ }^{ }$Senior Teaching and Research Assistant Clinic of Fixed and Removable Prosthodontics and Dental Material Science, Center of Dental Medicine, University of Zurich, Zurich, Switzerland. c Master Dental Technician, Division of Fixed Prosthodontics and Biomaterials, University Clinics for Dental Medicine, University of Geneva, Geneva, Switzerland.

`Professor, Clinic of Fixed and Removable Prosthodontics and Dental Material Science, Center of Dental Medicine, University of Zurich, Zurich, Switzerland.

'Professor, Division of Fixed Prosthodontics and Biomaterials, University Clinics for Dental Medicine, University of Geneva, Geneva, Switzerland.

Corresponding author:

Dr Sven Mühlemann 
Clinic of Fixed and Removable Prosthodontics and Dental Material Science

Center of Dental Medicine

University of Zurich

Plattenstrasse 11

CH-8032 Zurich

SWITZERLAND

Email: sven.muehlemann@zzm.uzh.ch

Acknowledgments:

The authors thank Gisela Müller (Clinic of Fixed and Removable Prosthodontics and Dental Material Science, Center of Dental Medicine, University of Zurich, Switzerland). 
JPD 17-922

Randomized controlled clinical trial of digital and conventional workflows for the fabrication of zirconia-ceramic posterior fixed partial dentures. Part II: Time efficiency of CAD-CAM versus conventional laboratory procedures

\section{ABSTRACT}

Statement of problem. Clinical trials are needed to evaluate the digital and conventional fabrication technology for providing fixed partial dentures (FPDs).

Purpose. The purpose of the second part of this clinical study was to compare the laboratory production time for tooth-supported, 3-unit FPDs by means of computer-aided design and computer-aided manufacturing (CAD-CAM) systems and a conventional workflow. In addition, the quality of the 3-unit framework of each treatment group was evaluated clinically. Material and methods. For each of 10 participants, a 3-unit FPD was fabricated. Zirconia was used as the framework material in the CAD-CAM systems and included Lava C.O.S. CAD software (3M) and centralized CAM (group L); CARES CAD software (Institut Straumann AG) and centralized CAM (group iT); and CEREC Connect CAD software (Dentsply Sirona) and centralized CAM (group C). The noble metal framework in the conventional workflow (group K) was fabricated by means of the traditional lost-wax technique. All frameworks were evaluated clinically before veneering. The time for the fabrication of the cast, the 3-unit framework, and the veneering process was recorded. In addition, chairside time during the clinical appointment for the evaluation of the framework was recorded. The paired Wilcoxon test together with appropriate Bonferroni correction was applied to detect differences among treatment groups $(\alpha=.05)$.

Results. The total effective working time (mean \pm standard deviation) for the dental technician was $220 \pm 29$ minutes in group L, $217 \pm 23$ minutes in group iT, $262 \pm 22$ minutes in group C, and $370 \pm 34$ minutes in group $\mathrm{K}$. The dental technician spent significantly more time in the 
conventional workflow than the digital workflow, independently of the CAD-CAM systems used $(P<.001)$.

Conclusions. Irrespective of the CAD-CAM system, the overall laboratory time for the dental technician was significantly less for a digital workflow than for the conventional workflow.

\section{CLINICAL IMPLICATIONS}

The fabrication of zirconia frameworks for posterior 3-unit FPDs is more time efficient for the dental technician using CAD-CAM systems than the fabrication of a conventional noble alloy framework using the lost-wax technique. The shipping time for the zirconia framework in CAD-CAM systems involving a centralized production facility may need to be considered.

\section{INTRODUCTION}

As zirconia restorations cannot be made with conventional fabrication techniques, it was only in the 1990s that computer-aided design and computer-aided manufacturing (CAD-CAM) technology allowed the introduction of zirconia as a dental prosthetic material. ${ }^{1}$ Zirconia has excellent mechanical properties and can therefore be successfully used as a dental framework material. ${ }^{2,3}$

Multiunit prostheses are generally fabricated in the dental laboratory. The start of the CAD-CAM process depends on the location of the scanner. Intraoral digital scanners allow dentists to make intraoral scans of the tooth preparations. ${ }^{4}$ Subsequently, the data file is digitally transferred to the dental laboratory, where the dental technician uses an associated CAD-CAM system to fabricate the multiunit prosthesis. In a traditional workflow, the dentist makes an intraoral impression with an elastomeric material and transfers it to the dental laboratory. The dental technician pours a stone cast, which may be digitized by a laboratory scanner for further processing with a CAD-CAM system or used for conventional fabrication of the prosthesis. ${ }^{5}$ Within a digital workflow, CAD software allows the dental technician to 
design the zirconia framework virtually. The virtual design of the zirconia framework can be replaced by a traditional wax pattern of the framework. Thereafter, in the digital copy milling system, referred to as CAM-only systems, the digital file of the scanned wax pattern serves as basis for the milling of the framework. ${ }^{6}$ Inevitably, the fabrication process of zirconia frameworks involves a CAM process.

Zirconia frameworks are milled from prefabricated zirconia blanks. Current CAM systems process the zirconia in a presintered state because the sintered material has high strength and hardness, which would make milling inefficient and wear the milling tools. ${ }^{7}$ An accurate milling process for a zirconia framework plays a key role in time efficiency in the dental laboratory as it may reduce manual laboratory steps. Time, effort, and accuracy differ depending on the type of the CAM procedure used for manufacturing zirconia FPDs. ${ }^{8} \mathrm{CAD}$ CAM systems with a 5-axis milling unit produce zirconia crowns with significantly lower mean marginal discrepancies than those made with a 3-axis milling unit. ${ }^{9}$ A clinical study confirmed that 5 -axis milling devices yield better accuracy than 4-axis milling units. ${ }^{10}$

Different CAD-CAM production routes exist for zirconia prostheses. In a laboratory workflow, the milling unit may be located in the dental laboratory (in-laboratory production) or in an industrial milling center (centralized production). An in vitro study showed that the location of the CAM system for the production of zirconia FPDs had a significant influence on the fit of the prosthesis. ${ }^{11}$ Laboratory-based production showed the best marginal accuracy of the systems studied. In a clinical study, monolithic crowns were fabricated using 4 different CAD-CAM workflows. ${ }^{12}$ Chairside milling resulted in less favorable prosthesis fit than centralized milling. However, the time needed for clinical evaluation by the dentist was similar. $^{13}$

Computerized technology allows laboratory procedures to be done anywhere in the world, enabling prostheses to be fabricated where production costs are low. However, despite the use of standardized CAD-CAM systems in the laboratories evaluated, a large variability of 
the framework quality has been reported, ${ }^{14}$ leading to increased time spent adjusting the framework. ${ }^{14}$

Nevertheless, CAD-CAM technology has the potential to reduce laboratory time as time-consuming manual laboratory steps can be avoided. Clinical studies evaluating the time efficiency of laboratory manufacturing processes comparing CAD-CAM technology and conventional workflows are scarce. A clinical study evaluated 5 different laboratory CADCAM systems and the conventional workflow for the fabrication of a monolithic crown. ${ }^{13}$ The dental technician spent significantly more time with the conventional workflow (mean 148 minutes) than the CAD-CAM processes (range of means between (74 and 92 minutes). The improved efficiency may compensate for the large financial outlay for CAD-CAM technology. ${ }^{15}$ However, the authors are unaware of studies on time efficiency for the laboratory-based fabrication of multiunit zirconia prostheses. Therefore, the purpose of this clinical study was to evaluate time efficiency for a 3-unit FPD fabricated by means of 3 different CAD-CAM systems and a conventional workflow. The null hypothesis was that the choice of CAD-CAM system or traditional manual workflow would have no effect on the laboratory production time.

\section{MATERIAL AND METHODS}

This study was the second part of a series of connected investigations that compared the digital and conventional workflows for the fabrication of a posterior 3-unit FPD. Part I of the investigation focused on the clinical time efficiency of digital scans versus conventional impressions. ${ }^{16}$ Part II analyzed the time and effort involved in the technical workflows for the fabrication of the 3-unit zirconia FPDs, and Part III assessed the marginal and internal discrepancy of the digitally and conventionally fabricated frameworks with the replica technique. ${ }^{17}$ Ten participants requiring a 3-unit posterior FPD were recruited to the study. All participants were informed about the study protocol, and written informed consent was 
obtained. The study protocol was approved by the local ethical committee of the University of Zurich, Switzerland (Ref. KEK-ZH_Nr. 2011-0103/5).

The abutment teeth for the zirconia FPDs were prepared according to the guidelines published for ceramic FPDs fabricated by CAD-CAM procedures (Sturzenegger B, et al. Swiss Dent J 2000;110:131-9). Abutment teeth were prepared with a 1-mm-wide shoulder preparation with rounded internal angles, a 10-degree total angle of convergence of the axial walls, and rounding of all line angles. Impressions were made with the double-cord technique in a randomized sequence (for more details see Part 1). ${ }^{16}$

Three different digital workflows, including an intraoral digital scanner and the corresponding CAD-CAM system, were evaluated for the fabrication of a 3-unit zirconia FPD: test group L, digital scanner Lava C.O.S. (3M) and CAD software (Lava C.O.S. v3.0; 3M); centralized milling process (Lava Milling Center; Rainer Rominger) of zirconia (Lava zirconia; 3M); test group iT, digital scanner Cadent iTero (Align Technologies Inc) and CAD software (CARES Visual v6.2; Institut Straumann AG); centralized milling process of zirconia (Zerion; Institut Straumann AG); and test group C, digital scanner Cerec Bluecam (Dentsply Sirona) and CAD software (Cerec Connect v4.0.3; Dentsply Sirona) and Cerec inLab 3D (Cerec inLab 3D v4.0.3; Dentsply Sirona); centralized milling process (infiniDent; Dentsply Sirona) of zirconia (inCoris ZI; Dentsply Sirona).

One dental technician (V.F.) performed all laboratory steps for the fabrication of the 3unit FPDs. The dental technician had several years of experience in fabricating prostheses with the CAD-CAM systems tested and the conventional lost-wax technique. This part of the study encompassed recording the time (in minutes) for each of the laboratory manufacturing steps of the digital and conventional workflows.

In the digital workflow, the time for the virtual design of the definitive cast (time for cast design) and the time until shipping of the definitive cast from the centralized manufacturer was recorded (shipping time of cast). In the conventional workflow, 
impressions were poured (Quadro-rock Plus; Picodent GmbH) and trimmed. After they had been embedded in a prefabricated tray (Pico Fix-Tray; Picodent GmbH), the definitive casts were mounted in an articulator (SAM3; SAM Präzisionstechnik GmbH). Similarly, the time for the fabrication of the framework was evaluated.

The CAD software of each digital workflow was used to design the framework of the 3-unit FPD (time for framework design). Thereafter, the time until arrival of the sintered CAD-CAM frameworks from the manufacturer's milling center and the shipping time of the framework was recorded. The frameworks were mounted on the articulated casts to manually produce an occlusal registration (Duralay; Reliance Dental Manufacturing LLC). The conventional framework was fabricated by the conventional lost-wax technique using a high noble alloy (Estheticor Special; Cendre Métaux SA).

Subsequently, 3 experienced clinicians (G.B., I.S., S.M.) qualitatively assessed the frameworks. Before the study started, the clinicians attended a training session to standardize the qualitative assessment and to calibrate the assessment techniques. Marginal integrity was assessed with a new dental explorer (DA470R; B. Braun Co). The correct alignment of the maxilla and mandible was evaluated from the occlusal registration. The time for the qualitative assessment was recorded. If necessary, chairside adjustments of the occlusal registration were allowed and clinical chairside time for adjustments was recorded. After the clinical evaluation, the dental technician was allowed to manually adjust the zirconia framework on the respective cast. Excessive contour was adjusted by reducing the framework and a marginal discrepancy was eliminated by reducing contacts in the intaglio surface of the framework. Inadequate contour was corrected by adding veneering ceramic. The framework was veneered using the framework material's specified veneering ceramic (zirconia: Creation ZI-F; Creation Willi Geller International GmbH; high noble alloy: Creation Classic; Creation Willi Geller International GmbH). The dental technician's time for the adaptation of the framework to the cast and the veneering of the framework was recorded. 
For statistical analysis, data were entered in a spreadsheet (Excel 15.0; Microsoft Corp) and analyzed with statistical software (IBM SPSS Statistics v20.0; IBM Corp). Continuous parameters were summarized by mean values and standard deviations. The discrete variables were described by absolute and relative frequencies. The KolmogorovSmirnov test was used to validate the normality assumption of the data. For both continuous and ordinal outcomes, the non-parametric paired Wilcoxon test together with an appropriate Bonferroni correction was applied to evaluate differences between treatment groups. If the assumption of normality was not rejected for continuous outcomes, the parametric paired $t$ test together with an appropriate Bonferroni correction was applied to evaluate differences between treatment groups ( $\alpha=.05$ for all tests).

\section{RESULTS}

Thirty CAD-CAM zirconia 3-unit FPDs and 10 conventional metal-ceramic posterior 3-unit FPDs resulting from 4 different manufacturing processes were fabricated. Four participants received a mandibular FPD and 6 maxillary. In all participants, the mesial abutment tooth was a premolar and the distal abutment tooth a molar. In 6 participants, the pontic site was a molar, whereas in 4 participants a premolar was replaced.

The mean time for the digital design of the cast ranged between $2 \pm 1$ minutes (group iT) and $13 \pm 3$ minutes (group L) (Table 1). Among the CAD-CAM systems, the cast design for group L took significantly more time than for group iT and group $\mathrm{C}(P=.001)$. The subsequent time for delivery of the CAD-CAM cast from the manufacturer to the dental laboratory ranged between 4.3 days (group iT) and 6.5 days (group L). The conventional casting procedure took significantly more time as compared with the digital cast design $(P<.001)$. In contrast, the waiting time for the conventional cast was significantly shorter compared with all the CAD-CAM casts $(P<.001)$,

The mean time for the virtual design of the framework ranged from $20 \pm 9$ minutes 
(group iT) to $38 \pm 2$ minutes (group C). No statistical significant difference was found among the CAD-CAM systems. The conventional workflow for the fabrication of the framework took significantly more time than any digital workflow $(P<.001)$. The shipping time from the manufacturer's milling center to the dental laboratory ranged between 4.0 days (group L) and 5.9 days (group C) and was significantly longer than the waiting time in the conventional workflow $(P<.001)$. At the clinical evaluation appointment, the mean treatment times ranged between $1.4 \pm 0.6$ (group L) and $1.9 \pm 0.5$ minutes (group C) (Table 2). The chairside time for adjustment ranged between $1.1 \pm 2.1$ minutes (group C) and $2.2 \pm 3.7$ minutes (group L) (Table 2). No statistically significant difference among treatment groups was detected $(P>.05)$. The clinical ratings are described by absolute frequencies in Table 2 . A statistically significant difference was found between the treatment groups for the parameter marginal integrity $(P<.001)$, which was better for conventionally fabricated frameworks with a score of perfect fit in 9 out of 10 as compared with the CAD-CAM fabricated zirconia frameworks in group L and group $\mathrm{C}(P<.001)$. No statistically significant difference was detected for the parameter occlusal registration.

The manual working time for the adaptation of the framework to the cast and the veneering of the framework ranged between $181 \pm 13$ minutes (group L) and $219 \pm 16$ minutes (group C) (Table 1). This laboratory process took significantly more time for group $\mathrm{C}$ than for any other group $(P<.001)$. Taking every fabrication step into account, the total working time for the dental technician ranged between $217 \pm 23$ minutes (group iT) and $262 \pm 22$ minutes (group C) with a digital workflow (Table 1, Fig. 1). With $370 \pm 34$ minutes, the dental technician spent significantly more working time in the conventional workflow than in the digital workflow, independently of the CAD-CAM system used $(P<.001)$.

\section{DISCUSSION}


The present study showed significant differences of the laboratory working time for the fabrication of a 3-unit FPD with CAD-CAM technology as compared with conventional manual procedures. Considering the laboratory working time, the digital workflow was more time efficient, independently of the CAD-CAM system used. Therefore, the null hypothesis was rejected.

The present study confirmed the results of a previous clinical study in which the time efficiency of 5 different laboratory CAD-CAM processes and the conventional pathway for the fabrication of a monolithic crown were evaluated. The dental technician spent significantly more time with the conventional workflow. ${ }^{13}$ Similarly, in the present study the conventional workflow resulted in a significantly increased mean working time of 370 minutes as compared with the CAD-CAM workflow, which ranged from 217 to 262 minutes. The digital design of the cast and the framework allowed a significant reduction of the working time in a digital workflow as compared with the conventional casting and lost-wax procedures.

The qualitative assessment revealed that the margins of the zirconia framework fabricated with CAD-CAM were predominantly excessively contoured. Marginal integrity was significantly worse in 2 CAD-CAM systems as compared with the conventional treatment group. However, the design of the margins may be affected by different digital parameter settings and different software versions, as reported in an in vitro study. ${ }^{18}$ To ensure standardization, the same software version of each CAD-CAM with default settings was used for all participants.

The working time for the veneering process was similarly independent of the fabrication process of the framework. However, in one CAD-CAM system, significantly more time was needed. At group C, an increased time for manual adaptation of the zirconia margins was necessary to improve marginal integrity before the veneering process. The results confirm that despite the use of standardized CAD-CAM systems, a large variation in 
framework quality may be expected. ${ }^{14}$ Consequently, the time efficiency in the digital workflow may be mitigated. Furthermore, manual adjustments may negatively affect the strength of the zirconia prosthesis. ${ }^{19}$ All CAD-CAM systems encompassed a centralized production facility resulting in a waiting time until the zirconia framework was shipped to the dental laboratory.

In the conventional workflow, the dental technician had to spend more time preparing and fabricating the cast and framework. However, the definitive cast and the noble alloy framework were available for the next step immediately after fabrication. Different laboratory CAM systems are available for the fabrication of digital casts and zirconia prostheses. ${ }^{20} \mathrm{~A}$ clinical study reported that a laboratory milling unit in a digital workflow improves time efficiency because the shipping time can be eliminated. ${ }^{13}$ The present study confirmed that a centralized manufacturing process increased the production time.

The precision of the milling process affects the quality of the zirconia framework. Centralized manufacturing may provide higher quality zirconia prostheses because of the industrial manufacturing. An in vitro study reported, however, that zirconia frameworks fabricated in the dental laboratory exhibited significantly better marginal fit than frameworks milled in a centralized location. ${ }^{11}$ Nevertheless, the marginal integrity of a digitally fabricated zirconia framework is not only dependent on the manufacturing process but also on the settings of the digital parameters in the design process. In the present study, the use of default settings in the design process may have affected the outcome in the qualitative assessment.

The veneering process is the most time-consuming factor in the fabrication of a 3-unit FPD. More translucent zirconias have been developed providing improved esthetics and allowing a monolithic design. ${ }^{21}$ Therefore, multiunit zirconia prostheses may be constructed in a monolithic design eliminating the veneering process. Finishing the monolithic prosthesis is limited to manual adjustments and characterization procedures. However, a clinical study showed that the finishing procedures of monolithic glass ceramic crowns may take between 
50 and 76 minutes. ${ }^{13}$ The time efficiency may have been further improved if a monolithic design had been chosen.

As with any computerized technology, CAD-CAM systems are constantly improving. ${ }^{22}$ Therefore, the results of the present study are limited to the software version at the time of the study. Additional clinical studies are necessary to evaluate the CAD-CAM technology as compared with the conventional workflow with regard to time efficiency and output quality.

\section{CONCLUSIONS}

Within the limitations of this clinical study, the following conclusions were drawn:

1. The overall laboratory working time in a digital workflow is significantly shorter than with a conventional workflow.

2. A centralized manufacturing process significantly reduces overall time efficiency.

3. The marginal integrity of CAD-CAM fabricated zirconia frameworks was rated significantly worse than that of conventionally fabricated noble alloy frameworks. 


\section{REFERENCES}

1. Filser F, Lüthy H, Schärer P, Gauckler LJ. All-ceramic bridges by direct ceramic machining (DCM). Materials and medicine Zurich: Hochschulverlag ETH 1998:165-89.

2. Sailer I, Makarov NA, Thoma DS, Zwahlen M, Pjetursson BE. All-ceramic or metal-ceramic tooth-supported fixed dental prostheses (FDPs)? A systematic review of the survival and complication rates. Part I: Single crowns (SCs). Dent Mater 2015;31:603-23.

3. Pjetursson BE, Sailer I, Makarov NA, Zwahlen M, Thoma DS. All-ceramic or metal-ceramic tooth-supported fixed dental prostheses (FDPs)? A systematic review of the survival and complication rates. Part II: Multiple-unit FDPs. Dent Mater 2015;31:624-39.

4. Benic GI, Muhlemann S, Fehmer V, Hammerle CH, Sailer I. Randomized controlled withinsubject evaluation of digital and conventional workflows for the fabrication of lithium disilicate single crowns. Part I: digital versus conventional unilateral impressions. J Prosthet Dent 2016;116:777-82.

5. Ha SJ, Cho JH. Comparison of the fit accuracy of zirconia-based prostheses generated by two CAD/CAM systems. J Adv Prosthodont 2016;8:439-48.

6. Castillo de Oyague R, Sanchez-Jorge MI, Sanchez Turrion A, Monticelli F, Toledano M, Osorio R. Influence of CAM vs. CAD/CAM scanning methods and finish line of tooth preparation in the vertical misfit of zirconia bridge structures. Am J Dent 2009;22:79-83.

7. Denry I, Kelly JR. State of the art of zirconia for dental applications. Dent Mater 2008;24:299-307.

8. Buchi DL, Ebler S, Hammerle CH, Sailer I. Marginal and internal fit of curved anterior CAD/CAM-milled zirconia fixed dental prostheses: an in-vitro study. Quintessence Int 2014;45:837-46.

9. Hamza TA, Ezzat HA, El-Hossary MM, Katamish HA, Shokry TE, Rosenstiel SF. Accuracy of ceramic restorations made with two CAD/CAM systems. J Prosthet Dent 2013;109:83-7. 
10. Kirsch C, Ender A, Attin T, Mehl A. Trueness of four different milling procedures used in dental CAD/CAM systems. Clin Oral Investig 2017;21:551-8.

11. Kohorst P, Junghanns J, Dittmer MP, Borchers L, Stiesch M. Different CAD/CAMprocessing routes for zirconia restorations: influence on fitting accuracy. Clin Oral Investig 2011;15:527-36.

12. Zeltner M, Sailer I, Muhlemann S, Ozcan M, Hammerle CH, Benic GI. Randomized controlled within-subject evaluation of digital and conventional workflows for the fabrication of lithium disilicate single crowns. Part III: marginal and internal fit. J Prosthet Dent 2017;117:354-62.

13. Sailer I, Benic GI, Fehmer V, Hammerle CHF, Muhlemann S. Randomized controlled within-subject evaluation of digital and conventional workflows for the fabrication of lithium disilicate single crowns. Part II: CAD-CAM versus conventional laboratory procedures. J Prosthet Dent 2017;118:43-8.

14. Schneebeli E, Bragger U, Scherrer SS, Keller A, Wittneben JG, Hicklin SP. Quality evaluation of zirconium dioxide frameworks produced in five dental laboratories from different countries. J Prosthodont 2017;26:399-409.

15. Abduo J, Lyons K. Rationale for the use of CAD/CAM technology in implant prosthodontics. Int J Dent 2013;2013:768121.

16. Sailer I, Mühlemann S, Fehmer V, Hammerle C, Benic GI. Randomized controlled clinical trial of digital and conventional workflows for the fabrication of zirconia-ceramic posterior fixed partial dentures. Part I: Time efficiency of complete arch digital scans versus conventional impressions. J Prosthet Dent 2018;submitted.

17. Benic GI, Sailer I, Zeltner M, Gütermann JN, Mühlemann S. Randomized controlled clinical trial of digital and conventional workflows for the fabrication of zirconia-ceramic fixed partial dentures. Part III: Marginal and internal fit. J Prosthet Dent 2018;submitted. 
18. Shim JS, Lee JS, Lee JY, Choi YJ, Shin SW, Ryu JJ. Effect of software version and parameter settings on the marginal and internal adaptation of crowns fabricated with the CAD/CAM system. J Appl Oral Sci 2015;23:515-22.

19. Kohorst P, Butzheinen LO, Dittmer MP, Heuer W, Borchers L, Stiesch M. Influence of preliminary damage on the load-bearing capacity of zirconia fixed dental prostheses. $\mathrm{J}$ Prosthodont 2010;19:606-13.

20. Fasbinder DJ. Digital dentistry: innovation for restorative treatment. Compend Contin Educ Dent 2010;31 Spec No 4:2-11; quiz 2.

21. Zhang Y. Making yttria-stabilized tetragonal zirconia translucent. Dent Mater 2014;30:1195-203.

22. van Noort R. The future of dental devices is digital. Dent Mater 2012;28:3-12. 


\section{TABLES}

Table 1. Time efficiency for fabrication of 3-unit FPD in the dental laboratory

\begin{tabular}{|c|c|c|c|c|c|c|}
\hline \multirow{2}{*}{$\mathrm{n}=10$} & \multirow{2}{*}{$\begin{array}{l}\text { cast fabrication } \\
\text { cast design }\end{array}$} & \multirow{2}{*}{$\begin{array}{l}\text { Shipping time for } \\
\text { cast }\end{array}$} & \multicolumn{2}{|c|}{$\begin{array}{l}\text { 3-unit fixed partial denture } \\
\text { fabrication }\end{array}$} & \multirow{2}{*}{$\begin{array}{l}\text { Shipping } \\
\text { time for } \\
\text { framework }\end{array}$} & \multirow{2}{*}{ Total working time } \\
\hline & & & $\begin{array}{l}\text { framework } \\
\text { design }\end{array}$ & $\begin{array}{l}\text { ceramic } \\
\text { veneering }\end{array}$ & & \\
\hline & \multicolumn{6}{|c|}{ mean $\pm \mathrm{SD}(95 \% \mathrm{CI})$} \\
\hline $\begin{array}{l}\text { Group } \\
\text { L }\end{array}$ & $\begin{array}{l}13 \pm 3 * \\
(11-15)\end{array}$ & $\begin{array}{l}9306 \pm 223 * \\
(5388-13224)\end{array}$ & $\begin{array}{l}27 \pm 26^{*} \\
(8-45)\end{array}$ & $\begin{array}{l}181 \pm 13^{*} \\
(171-190)\end{array}$ & $\begin{array}{l}5700 \\
\pm 2499 * \\
(3912-7488)\end{array}$ & $\begin{array}{l}220 \pm 29 * \\
(199-241)\end{array}$ \\
\hline $\begin{array}{l}\text { Group } \\
\text { iT }\end{array}$ & $\begin{array}{l}2 \pm 1 * \\
(1-3)\end{array}$ & $\begin{array}{l}6194 \pm 1587 * \\
(5058-7329)\end{array}$ & $\begin{array}{l}20 \pm 9 * \\
(14-27)\end{array}$ & $\begin{array}{l}195 \pm 19 * \\
(182-208)\end{array}$ & $\begin{array}{l}5978 \\
\pm 1778^{*} \\
(4705-6603)\end{array}$ & $\begin{array}{l}217 \pm 23 * \\
(201-234)\end{array}$ \\
\hline $\begin{array}{l}\text { Group } \\
\text { C }\end{array}$ & $\begin{array}{l}5 \pm 4 * \\
(2-8)\end{array}$ & $\begin{array}{l}6553 \pm 3277 * \\
(4209-8897)\end{array}$ & $\begin{array}{l}38 \pm 8^{*} \\
(32-44)\end{array}$ & $\begin{array}{l}219 \pm 16^{*} \\
(108-230)\end{array}$ & $\begin{array}{l}8523 \\
\pm 3415^{*} \\
(6081- \\
10966) \\
\end{array}$ & $\begin{array}{l}262 \pm 22 * \\
(246-278)\end{array}$ \\
\hline $\begin{array}{l}\text { Group } \\
\mathrm{K}\end{array}$ & $\begin{array}{l}37 \pm 5 * \\
(33-40)\end{array}$ & $135 *$ & $\begin{array}{l}138 \pm 14 * \\
(128-149)\end{array}$ & $\begin{array}{l}195 \pm 25^{*} \\
(177-212)\end{array}$ & $285 *$ & $\begin{array}{l}370 \pm 34 * \\
(346-394)\end{array}$ \\
\hline
\end{tabular}

C, Cerec Connect CAD software. iT, Cares CAD software. K, conventional fabrication. L, Lava C.O.S CAD software.

Different superscript letters per column represent statistically significant differences $(P<.05)$ between treatment groups (paired Wilcoxon test together with appropriate Bonferroni correction) 
Table 2. Clinical assessment of frameworks and time efficiency

\begin{tabular}{|c|c|c|c|c|c|c|c|c|}
\hline \multirow{3}{*}{$\mathrm{n}=10$} & \multirow{3}{*}{$\begin{array}{l}\begin{array}{l}\text { Clinical } \\
\text { evaluation }\end{array} \\
\text { time (min) } \\
\text { mean } \pm \text { SD } \\
(95 \% \mathrm{CI})\end{array}$} & \multicolumn{6}{|c|}{ Qualitative assessment } & \multirow{3}{*}{$\begin{array}{l}\text { Chairside adjustments } \\
\text { time (min) } \\
\text { mean } \pm \mathrm{SD} \\
(95 \% \mathrm{CI})\end{array}$} \\
\hline & & \multicolumn{3}{|c|}{ marginal integrity $(\mathrm{n}=10)$} & & \multicolumn{2}{|c|}{$\begin{array}{l}\text { occlusal registration } \\
(\mathrm{n}=10)\end{array}$} & \\
\hline & & $\begin{array}{l}\text { perfect } \\
\text { fit }\end{array}$ & $\begin{array}{l}\text { over- } \\
\text { /undercontou } \\
\mathrm{r}\end{array}$ & gap & & correct & $\begin{array}{l}\text { incorre } \\
\text { ct }\end{array}$ & \\
\hline $\begin{array}{l}\text { Group } \\
\text { L }\end{array}$ & $\begin{array}{l}1.8 \pm 0.6 \\
(1.4-2.25)\end{array}$ & 0 & $9 / 0$ & 1 & $\mathrm{~b}$ & 8 & 2 & $\begin{array}{l}2.2 \pm 3.7 \\
(0.2-4.9)\end{array}$ \\
\hline $\begin{array}{l}\text { Group } \\
\text { iT }\end{array}$ & $\begin{array}{l}1.6 \pm 0.5 \\
(1.3-2.0)\end{array}$ & 5 & $2 / 1$ & 2 & $a, b$ & 9 & 1 & $\begin{array}{l}1.9 \pm 2.8 \\
(0.1-3.9)\end{array}$ \\
\hline $\begin{array}{l}\text { Group } \\
\text { C }\end{array}$ & $\begin{array}{l}1.9 \pm 0.5 \\
(1.5-2.2) \\
\end{array}$ & 1 & $9 / 0$ & 0 & $\mathrm{~b}$ & 8 & 2 & $\begin{array}{l}1.1 \pm 2.1 \\
(0-2.6)\end{array}$ \\
\hline $\begin{array}{l}\text { Group } \\
\mathrm{K}\end{array}$ & $\begin{array}{l}1.4 \pm 0.6 \\
(1.1-1.8)\end{array}$ & 9 & $1 / 0$ & 0 & $\mathrm{a}$ & 9 & 1 & $\begin{array}{l}1.5 \pm 2.3 \\
(0.1-3.2)\end{array}$ \\
\hline
\end{tabular}

: C, Cerec Connect CAD software; iT, Cares CAD software; K, conventional fabrication; L, Lava C.O.S CAD software

Statistically significant differences between treatment groups were calculated for parameter marginal integrity. Different letters $(a, b)$ represent statistically significant differences $(P<.05)$ 


\section{FIGURES}

Figure 1.

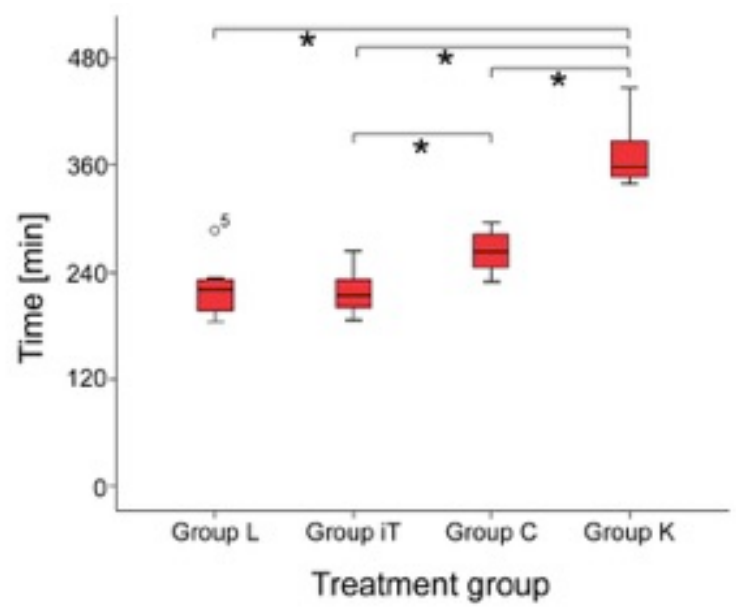

C, Cerec Connect CAD software. iT, Cares CAD software. K, conventional fabrication. L, Lava C.O.S CAD software.

Statistically significant differences $(P<.05, *)$ between treatment groups (paired Wilcoxon test together with appropriate Bonferroni correction). 